\title{
The level of emotion control, anxiety, and self- efficacy in the elderly in Bialystok, Poland
}

This article was published in the following Dove Press journal:

Clinical Interventions in Aging

8 February 2017

Number of times this article has been viewed

\author{
Mateusz Cybulski' \\ Lukasz Cybulski² \\ Elzbieta Krajewska-Kulak' \\ Urszula Cwalina ${ }^{3}$ \\ 'Department of Integrated Medical \\ Care, Faculty of Health Sciences, \\ Medical University of Bialystok, \\ Bialystok, ${ }^{2}$ Faculty of Social Sciences, \\ University of Warmia and Mazury, \\ Olsztyn, ${ }^{3}$ Department of Statistics \\ and Medical Informatics, Faculty of \\ Health Sciences, Medical University of \\ Bialystok, Bialystok, Poland
}

Purpose: The aim of the study was to assess the level of emotion control, anxiety, and selfefficacy in the inhabitants of Bialystok (Poland) aged above 60.

Patients and methods: The study included 300 people above the age of 60, inhabitants of Bialystok and its neighborhoods: 100 residents of public nursing home, 100 participants of the University of the Third Age in Bialystok, and 100 students of the University of Healthy Senior. The three standardized psychometric scales were used in the study: Courtauld Emotional Control Scale (CECS), State-Trait Anxiety Inventory (STAI), and General SelfEfficacy Scale (GSES).

Results: The median of the overall score of CECS equaled 54 points, which is considered average in terms of negative emotions acceptance. The mean score of perceiving anxiety as the condition of STAI (X1) was 48 points, while anxiety as a trait of STAI (X2) was 49 points. The overall score for GSES proved that respondents had a subjective feeling of self-efficacy at the level of 29 points out of 40 points possible, which means that their self-efficacy was rather at the high level in their self-assessment. In women, a negative correlation was revealed between the sense of self-efficacy and age $(r=-0.320, P<0.001)$. Analyzing the study group affiliation of respondents, a negative correlation was reported between the sense of self-efficacy and age among the elderly residents of public nursing home $(r=-0.408, P<0.001)$. Taking into consideration the study group affiliation of respondents, a positive correlation between anger control (CECS) and the sense of anxiety as a trait of STAI (X2) was found among participants of the University of Healthy Senior $(r=0.307, P=0.002)$.

Conclusion: The social and demographic features (gender, group affiliation, age) analyzed in the study were found to be correlated significantly with the control of negative emotions, the level of anxiety, and self-efficacy. The study group affiliation was a key variable conditioning the relations between the analyzed features. The elderly residents of public nursing home belonged to the group distinguishing negatively compared to other two study groups. The study respondents were characterized by the relatively high perception of anxiety, which may be as a result of the health and social problem present in this age group. In order to improve the quality of life, the study population should reduce level of perceived anxiety and increase the control of negative emotions and self-efficacy by social integration of seniors. The study scores in the scale of CECS, STAI, and GSES do not deviate from the world norms obtained by other researchers in the rest of the world.

Keywords: emotion control, level of anxiety, the elderly, old age, self-efficacy

\section{Introduction}

Population aging poses a significant challenge to public health, both in social and health aspect. It is projected that by 2050 , the people aged above 60 will constitute $80 \%$ of the whole population in the countries of medium and low income. In the analyses of the World Health Organization, Japan is indicated as an example of
Correspondence: Mateusz Cybulski Department of Integrated Medical Care Faculty of Health Sciences, Medical University of Bialystok, SklodowskiejCurie 7a Street, 15-096 Bialystok, Poland $\mathrm{Tel}+48856865103$

Fax +48 857485528

Email mateusz.cybulski@umb.edu.pl 
the country where now as many as $30 \%$ of the population is above 60 years old. ${ }^{1}$ By 2050, similar rates will be observed in Chile, China, Iran, and Thailand, ${ }^{1}$ while the people aged above 65 will constitute more than $25 \%$ of the population of the whole European region. ${ }^{2}$ By 2020 , more than one million Poles will be 90 years old, and by 2035 more than $25 \%$ of Poles will be 65 years older or more. In 2060, Poles will be one of the oldest populations in Europe. ${ }^{3}$

Neurodegenerative and neuropsychiatric conditions that can affect older people, such as dementia, multiple sclerosis, schizophrenia, and Parkinson's disease, are often characterized by significant psychological deficits that reduce significantly patients' abilities and their overall quality of life..$^{4-7}$

The role of emotion in the genesis of lesions in somatic and psychosomatic diseases has been explained relatively well. ${ }^{8}$ Suppression of emotions, especially, negative emotions, is closely associated with a phenomenon of distress, a prolonged reaction to stress, which may devastate the human body and contribute to development of psychosomatic diseases. ${ }^{9}$ Watson and Greer ${ }^{10}$ proved that emotion suppression is a factor determining individual differences in the level of psychological distress. The expressive display of emotions is associated with a low sense of psychological distress. ${ }^{11}$

The sense of anxiety is another psychological feeling associated with suffering and mental discomfort, ${ }^{12,13}$ and as a psychological trait refers to individual differences in response to stressful situations, ${ }^{9}$ as eg, comorbidity among the elderly. Anxiety is an unpleasant emotional state which encompasses physical, cognitive, and behavioral symptoms, such as, disorders of emotional regulation, especially, in interpersonal, ambiguous, and dangerous situations. ${ }^{14}$ Excessive fear that causes suffering or interferes with everyday tasks is not a normal element of aging and may lead to the development of new health problems and worsen daily functioning. Richardson et al's ${ }^{15}$ study proved that more than $27 \%$ of the elderly under care of attendants showed anxiety symptoms, which greatly influenced their functioning.

A high level of anxiety affects significantly perceived selfefficacy, because the higher the level of anxiety the elderly have, the lower the level of self-efficacy they show. The people with a low level of self-efficacy perceive potential difficulties as obstacles overgrowing their capabilities, thus they decrease their efforts or even resign from the activity. ${ }^{16}$ Self-efficacy helps to anticipate intentions and activities within various areas of the human activity, including healthy behavior. It can be generally assumed that perceived selfefficacy is an indicator of intentions and activities within various areas of healthy behavior. Both the intention of engagement in defined healthy activities and current behavior are positively associated with beliefs about self-efficacy. Concurrently, beliefs about self-efficacy influence selfassessment of an individual's own resources in a stressful situation. ${ }^{17}$ As Locke and Latham ${ }^{18}$ emphasize, the stronger the beliefs about self-efficacy, the higher the goals people put and the greater their involvement in the intended behavior, even facing failures.

The aim of this study was to assess the level of emotion control, anxiety, and self-efficacy in the elderly aged above 60 who are inhabitants of Bialystok (Poland). In reference to the aim of the study, we formulated the following hypothesis to test via questionnaire-based study:

The level of emotion control, anxiety, and self-efficacy will be negatively characterized in the elderly aged above 60 who are inhabitants of Bialystok and will depend on the sociodemographic characteristics of respondents.

We assumed that the group characterized by the worst values were residents of a nursing home.

\section{Patients and methods}

\section{Participants}

The study was carried out on three groups:

- Group I-participants of the University of Healthy Senior (UHS) (100 people), held in the Faculty of Health Sciences of the Medical University of Bialystok and aimed at promoting healthy lifestyle and healthy attitude, widening the knowledge about health sciences, as well as social activation and prevention of loneliness among the elderly;

- Group II - students of the University of the Third Age (UTA) in Bialystok (100 people);

- Group III - the elderly residents of the public nursing home (PNH) at 9 Swierkowa str in Bialystok (100 people).

A total of 300 people aged above 60 - inhabitants of Bialystok and the neighborhoods - were included in the study.

An additional criterion for the inclusion to the study apart from the age and place of residence was lack of dementia. Each of the participants had to give a written consent to participate in the study and could withdraw from the study at any stage.

Similarly, other exclusion criteria of the study were: age below 60, place of residence outside Bialystok and its neighborhoods, and the presence of dementia.

The selection of respondents was purposeful. In order to have a representative study population, the authors collected 100 completely filled surveys in each subgroup. Among the students of the UTA and the UHS, more copies of the research 
tools were passed, but not all distributed questionnaires were returned to the authors of the study. Among the students of the UHS, 150 copies of questionnaires were distributed, and among the participants of the UTA, 200 copies.

\section{Measurements and procedure}

In the study, three standardized psychometric scales were used:

- Courtauld Emotional Control Scale (CECS) by M Watson and S Greer, adapted by Z Juczynski,

- State-Trait Anxiety Inventory (STAI) by CD Spielberger, adapted by J Strelau, M Tysarczyk, and K Wrzesniewski,

- General Self-Efficacy Scale (GSES) by R Schwarzer, M Jerusalem, adapted by Z Juczynski.

CECS consists of three subscales, each of them containing seven statements regarding the way of showing anger, depression, and anxiety. The scale is used to measure subjective control of anger, anxiety, and depression in difficult situations and designed to examine adults (both healthy and ill). CECS is a tool of self-description. Summing up the scores of all three subscales, the overall score of emotion control is established. ${ }^{17}$ The examination aims at defining to what degree an individual is convinced subjectively of ability to control his/her reactions in the situation of experiencing given negative emotions. The overall indicator of emotion control is within the range of $21-84$ points. The higher the score, the greater the suppression of negative emotions. Having assessed the reliability of the Polish scale via estimation of its internal compliance and absolute stability, the following $\alpha$ coefficients of Cronbach were established: 0.80 for anger control, 0.77 for depression, 0.78 for anxiety, and 0.87 for a total indicator of emotion control. ${ }^{17}$

STAI construction is based on differentiation between anxiety understood as an individual's temporary and situation-conditioned state and anxiety understood as a relatively permanent trait of a personality. In his concept, Spielberger referred to the studies carried earlier by Cattell. ${ }^{19}$ They highlighted two different factors. The first, responsible for changeability of scores from situation to situation, was called "anxiety as a state". The second, responsible for individual differences, was called "anxiety as a trait". STAI questionnaire consists of two independent parts, each containing 20 statements. The level of anxiety treated as a current emotional state can be examined by using of the first part of STAI (X-1). This part of the questionnaire is a very sensitive tool and helps to follow dynamics of anxiety within short time intervals. The second part of STAI (X-2) regards to anxiety understood as an individual's personality trait. ${ }^{20}$
The respondent relates to each statement selecting one of four possibilities. The level of anxiety is expressed by means of points obtained via summing up the points of particular answers. The point scores for each part of the questionnaire may range from 20 to 80 . The scores of the test are interpreted in the following way: the higher the score value, the higher the level of anxiety. The psychometric values of the test permit researchers to use it in the group studies. The reliability of the test examined by means of a coefficient of internal compliance ranges from 0.76 to 0.92 in the group of adult women and men Theoretical accuracy of X-1 scale equals 0.51 for men and 0.57 for women, respectively. ${ }^{20}$

GSES is composed of 10 statements. Contrary to the scales designated to measure self-efficacy in specific situations, GSES measures the strength of the individual's belief about coping with difficult situations and obstacles. The scale is designated to examine healthy and ill adults. A respondent marks the answers he/she selected by circling the right number. Each question is followed by four answers to select from: not -1 ; rather not -2 ; rather yes -3 , and yes $-4 .{ }^{17}$ The time required to complete the scale does not exceed 2-3 minutes. The sum of all points gives the overall indicator of self-efficacy, which is within the range of 10-40 points. The higher the score is, the higher the level of self-efficacy respondents show. ${ }^{17}$

The respondents from group I and II completed the questionnaires on their own. Additional explanations and instructions were placed in every questionnaire of the scale. The group III (the elderly residents of public nursing homes) respondents were interviewed directly by psychologists and occupational therapists employed in this institution.

\section{Procedure and ethical considerations}

The study was performed from February to June 2016. The research conforms with the Good Clinical Practice guidelines, and the procedures followed were in accordance with the Helsinki Declaration of 1975, as revised in 2000 (concerning the ethical principles for the medical community and forbidding releasing the name of the patient, initials, or the hospital evidence number) and following the ethical standards of the institutional committee on human experimentation. The study protocol was approved by the Bioethics Committee of the Medical University of Bialystok (statute no R-I-002/365/2015). Written informed consent was obtained from each respondent, in accordance with the Helsinki declaration.

\section{Statistical analysis}

The data were processed using Microsoft Excel 2013 (Microsoft Corporation, Redmond, WA, USA) program and 
analyzed statistically by means of Statistica Data Miner C QC PL program. The Pearson's $\chi^{2}$ test was used to analyze the dependence of quality features. The Shapiro-Wilk test was used to assess the normality of distribution of quantity features. Since no normality of distribution was established, these features were analyzed using nonparametric methods. Two groups were compared with the Mann-Whitney $U$-test, and three groups by means of analysis of variance and Kruskal-Wallis test together with post hoc tests. Additionally, Spearman's rank correlation coefficient was used. The results with $P \leq 0.05$ were regarded as statistically significant.

\section{Results}

The study included 213 (71\%) women and 87 (29\%) men. The median of the overall score of CECS equaled 54 points, which is considered average in terms of negative emotions acceptance. The mean score of subjective control of anger and anxiety was 18 out of 28 points. The analysis of STAI questionnaire proved that the overall score of perceiving anxiety as a state - STAI (X1) - was 48 points, while as a trait - STAI (X2) - it was of 49 points. When analyzing anxiety as a state, a score of 39-40 points suggested clinical symptoms of anxiety disorders. ${ }^{21,22}$ Additionally, it was found that men were characterized by a significantly lower value of anxiety as a trait STAI (X2) $(P=0.001)$. Other studies showed that in the elderly, the condition was suspected with a score range of 54-55 points. ${ }^{23}$ The overall score for GSES proved that respondents had a subjective sense of self-efficacy at 29 points out of 40 points, which means that self-efficacy was rather the high based on their own self-assessment. The detailed data for the whole group as well as men and women are presented in Table 1.

Taking into consideration the mean scores of the analyzed scales regarding the study group affiliation, the group of the participants of the UHS had the highest scores, whereas

Table I Mean score of CECS, STAI, and GSES with regard to gender

\begin{tabular}{|c|c|c|c|c|c|c|}
\hline \multirow[t]{2}{*}{$\begin{array}{l}\text { Psychometric } \\
\text { scales }\end{array}$} & \multicolumn{2}{|l|}{$\begin{array}{l}\text { Women } \\
N=213\end{array}$} & \multicolumn{2}{|l|}{$\begin{array}{l}\text { Men } \\
\mathbf{N}=\mathbf{8 7}\end{array}$} & \multicolumn{2}{|l|}{$\begin{array}{l}\text { Total } \\
\mathbf{N}=300\end{array}$} \\
\hline & $\bar{x} \pm \mathbf{S D}$ & Me & $\bar{x} \pm \mathbf{S D}$ & Me & $\bar{x} \pm \mathbf{S D}$ & Me \\
\hline CECS anger & $18.14 \pm 3.35$ & 18.0 & $|8.08 \pm 3.5|$ & 18.0 & $18.12 \pm 3.39$ & 18.0 \\
\hline CECS depression & $18.23 \pm 3.78$ & 19.0 & $17.71 \pm 3.66$ & 18.0 & $18.08 \pm 3.75$ & 18.0 \\
\hline CECS anxiety & $17.62 \pm 3.35$ & 18.0 & $17.34 \pm 3.15$ & 17.0 & $17.54 \pm 3.29$ & 18.0 \\
\hline CECS total & $53.99 \pm 8.54$ & 54.0 & $53.14 \pm 8.6$ & 53.0 & $53.74 \pm 8.55$ & 54.0 \\
\hline STAI (XI) & $48.1 \pm 4.3$ & 48.0 & $47.71 \pm 4.91$ & 48.0 & $47.99 \pm 4.48$ & 48.0 \\
\hline STAI (X2) & $49.25 \pm 4.5$ & 49.0 & $46.84 \pm 5.17$ & 47.0 & $48.55 \pm 4.82$ & 49.0 \\
\hline GSES & $28.11 \pm 6.04$ & 29.0 & $28.36 \pm 6.42$ & 30.0 & $28.18 \pm 6.14$ & 29.0 \\
\hline
\end{tabular}

Abbreviations: CECS, Courtauld Emotional Control Scale; GSES, General Self-Efficacy Scale; STAI, State-Trait Anxiety Inventory; SD, standard deviation; Me, median. elderly residents of public nursing home had the lowest scores. The figures are presented in Table 2. The statistical analysis proved statistically significant differences in subjective anger control (CECS) between the participants of UHS and the residents of PNH $(P=0.011)$, subjective depression control (CECS) between the students of UHS and the residents of PNH $(P<0.001)$ as well as between the residents of PNH and the participants of UTA $(P=0.009)$, subjective anxiety control (CECS) between the residents of PNH and the students of UHS $(P=0.007)$ as well as between the residents of PNH and the students of UTA $(P=0.003)$, subjective emotion control in total (CECS) between the residents of PNH and the participants of UHS $(P<0.001)$ as well as the residents of PNH and the participants of UTA $(P=0.002)$, perception of anxiety as a state (STAI-X1) between the students of UHS and the residents of PNH $(P=0.013)$, and also self-efficacy (GSES) between residents of $\mathrm{PNH}$ and the participants of UHS $(P<0.001)$ as well as the residents of PNH and the participants of UTA $(P<0.001)$.

The distribution of answers in case of the value analysis of individual scales regarding respondents' age is presented in Table 3. The study group with the most number of people as that in which subjects were aged 60-69 (above 50\%). The youngest respondent was 60 years old, while the oldest was 98 years old. In the study, the following statistically significant differences were reported in the age groups: in perception of anxiety as a state STAI (X1) between the respondents aged 60-69 and the respondents aged 80 and above $(P=0.003)$, and between respondents aged $70-79$ and the respondents above $80(P=0.016)$, as well as between selfefficacy in the same age groups (in both cases $P<0.001$ ).

In Table 4, the scores of GSES are presented regarding the level of self-efficacy according to gender, age, and study

Table 2 Mean scores of CECS, STAI, and GSES with regard to the study group

\begin{tabular}{|c|c|c|c|c|c|c|}
\hline \multirow[t]{2}{*}{$\begin{array}{l}\text { Psychometric } \\
\text { scales }\end{array}$} & \multicolumn{2}{|l|}{$\begin{array}{l}\text { UHS } \\
\mathbf{N}=100\end{array}$} & \multicolumn{2}{|l|}{$\begin{array}{l}\text { UTA } \\
\mathbf{N}=100\end{array}$} & \multicolumn{2}{|l|}{$\begin{array}{l}\text { PNH } \\
\mathrm{N}=100\end{array}$} \\
\hline & $\bar{x} \pm \mathbf{S D}$ & Me & $\bar{x} \pm \mathbf{S D}$ & Me & $\bar{x} \pm \mathbf{S D}$ & Me \\
\hline CECS anger & $18.72 \pm 3.64$ & 19.0 & $18.32 \pm 3.02$ & 19.0 & $17.32 \pm 3.35$ & 17.0 \\
\hline CECS depression & $18.95 \pm 3.9$ & 19.0 & $18.34 \pm 3.3$ & 18.0 & $16.96 \pm 3.77$ & 17.0 \\
\hline CECS anxiety & $17.76 \pm 3.76$ & 19.0 & $18 \pm 3.08$ & 19.0 & $16.85 \pm 2.88$ & 16.0 \\
\hline CECS total & $55.43 \pm 9.62$ & 56.0 & $54.66 \pm 7$ & 54.0 & $51.13 \pm 8.28$ & 51.0 \\
\hline STAI $(X I)$ & $48.8 I \pm 3.55$ & 48.5 & $47.97 \pm 5.35$ & 48.0 & $47.19 \pm 4.26$ & 47.0 \\
\hline STAI (X2) & $48.45 \pm 4.1$ & 49.0 & $48.8 \mathrm{I} \pm 5.7$ & 49.0 & $48.4 \pm 4.55$ & 48.0 \\
\hline GSES & $30.45 \pm 4.22$ & 30.0 & $29.7 I \pm 3.88$ & 30.0 & $24.38 \pm 7.67$ & 25.0 \\
\hline
\end{tabular}

Abbreviations: CECS, Courtauld Emotional Control Scale; GSES, General SelfEfficacy Scale; PNH, public nursing home; STAI, State-Trait Anxiety Inventory; UHS, University of Healthy Seniors; UTA, University of the Third Age; SD, standard deviation; Me, median. 
Table 3 Mean scores of CECS, STAI, and GSES with regard to the age of respondents

\begin{tabular}{|c|c|c|c|c|c|c|}
\hline \multirow[t]{2}{*}{$\begin{array}{l}\text { Psychometric } \\
\text { scales }\end{array}$} & \multicolumn{2}{|c|}{$\begin{array}{l}\text { 60-69 years } \\
\text { old } \\
N=154\end{array}$} & \multicolumn{2}{|c|}{$\begin{array}{l}\text { 70-79 years } \\
\text { old } \\
\mathrm{N}=102\end{array}$} & \multicolumn{2}{|c|}{$\begin{array}{l}80 \text { years old } \\
\text { and above } \\
N=44\end{array}$} \\
\hline & $\bar{x} \pm \mathbf{S D}$ & Me & $\bar{x} \pm \mathbf{S D}$ & Me & $\bar{x} \pm \mathbf{S D}$ & Me \\
\hline CECS anger & $18.36 \pm 3.3$ & 19.0 & $\mid 8.1 \pm 3.61$ & 18.0 & $17.32 \pm 3.1$ & 17.5 \\
\hline CECS depression & $18.47 \pm 3.7$ & 18.0 & $17.82 \pm 3.78$ & 18.0 & $17.32 \pm 3.73$ & 17.0 \\
\hline CECS anxiety & $17.44 \pm 3.56$ & 18.0 & $17.74 \pm 3.25$ & 18.0 & $17.43 \pm 2.27$ & 17.0 \\
\hline CECS total & $54.27 \pm 8.28$ & 54.0 & $53.66 \pm 9.16$ & 54.0 & $52.07 \pm 7.94$ & 52.0 \\
\hline STAI (XI) & $48.37 \pm 4.3$ & 48.5 & $48.16 \pm 4.24$ & 48.0 & $46.27 \pm 5.3$ & 45.5 \\
\hline STAI (X2) & $48.89 \pm 4.6$ & 49.0 & $47.64 \pm 5.18$ & 48.0 & $49.5 \pm 4.45$ & 49.0 \\
\hline GSES & $29.62 \pm 4.66$ & 30.0 & $28.43 \pm 5.43$ & 29.0 & $22.55 \pm 8.7$ & 23.5 \\
\hline
\end{tabular}

Abbreviations: CECS, Courtauld Emotional Control Scale; GSES, General SelfEfficacy Scale; STAI, State-Trait Anxiety Inventory; SD, standard deviation; Me, median.

Table 4 The level of self-efficacy in the respondents with regard to gender, study group affiliation, and age

\begin{tabular}{|c|c|c|c|c|}
\hline \multirow[t]{2}{*}{ Characteristic } & \multicolumn{3}{|c|}{ GSES scores } & \multirow[t]{2}{*}{$P$-values } \\
\hline & $\begin{array}{l}\text { Low } \\
\mathrm{N}=60\end{array}$ & $\begin{array}{l}\text { Average } \\
\mathrm{N}=91\end{array}$ & $\begin{array}{l}\text { High } \\
N=149\end{array}$ & \\
\hline Women & & & & 0.432 \\
\hline \multicolumn{5}{|l|}{$N=213$} \\
\hline $\mathrm{N}$ & 40 & 69 & 104 & \\
\hline$\%$ & $18.78 \%$ & $32.39 \%$ & $48.83 \%$ & \\
\hline \multicolumn{5}{|l|}{ Men } \\
\hline \multicolumn{5}{|l|}{$\mathrm{N}=87$} \\
\hline$N$ & 20 & 22 & 45 & \\
\hline$\%$ & $22.99 \%$ & $25.29 \%$ & $51.72 \%$ & \\
\hline UHS & & & & $<0.001$ \\
\hline \multicolumn{5}{|l|}{$\mathrm{N}=100$} \\
\hline $\mathrm{N}$ & 6 & 37 & 57 & \\
\hline$\%$ & $6.00 \%$ & $37.00 \%$ & $57.00 \%$ & \\
\hline \multicolumn{5}{|l|}{ UTA } \\
\hline \multicolumn{5}{|l|}{$N=100$} \\
\hline $\mathrm{N}$ & 7 & 32 & 61 & \\
\hline$\%$ & $7.00 \%$ & $32.00 \%$ & $61.00 \%$ & \\
\hline \multicolumn{5}{|l|}{ PNH } \\
\hline \multicolumn{5}{|l|}{$N=100$} \\
\hline$N$ & 47 & 22 & 31 & \\
\hline$\%$ & $47.00 \%$ & $22.00 \%$ & $31.00 \%$ & \\
\hline 60-69 years old & & & & $<0.001$ \\
\hline \multicolumn{5}{|l|}{$N=154$} \\
\hline $\mathrm{N}$ & 19 & 43 & 92 & \\
\hline$\%$ & $12.34 \%$ & $27.92 \%$ & $59.74 \%$ & \\
\hline \multicolumn{5}{|l|}{ 70-79 years old } \\
\hline \multicolumn{5}{|l|}{$\mathrm{N}=102$} \\
\hline $\mathrm{N}$ & 18 & 38 & 46 & \\
\hline$\%$ & $17.65 \%$ & $37.25 \%$ & $45.10 \%$ & \\
\hline \multicolumn{5}{|c|}{80 years old and above } \\
\hline \multicolumn{5}{|c|}{$\mathrm{N}=44$} \\
\hline $\mathrm{N}$ & 23 & 10 & 11 & \\
\hline$\%$ & $52.27 \%$ & $22.73 \%$ & $25.00 \%$ & \\
\hline
\end{tabular}

Abbreviations: GSES, General Self-Efficacy Scale; PNH, public nursing home; UHS, University of Healthy Seniors; UTA, University of the Third Age. group affiliation. No significant correlation was revealed between the score of GSES and gender. However, the study group affiliation (PNH, UHS, UTA) was found to be related significantly to the score on the GSES $(P<0.001)$. In the groups of UHS and UTA, more than half of respondents ( $57 \%$ and $61 \%$, respectively) had high score on GSES. Among residents of PNH, $47 \%$ of the questioned were characterized by a low level of self-efficacy. Moreover, a statistically significant correlation was reported between the score of GSES and age $(P<0.001)$. In the youngest age group $(60-69$ years old $)$, more than half of respondents $(59.74 \%)$ were characterized by a high level of self-efficacy. The reverse correlation was established in the oldest age group (above 80) - more than half of the questioned (52.27\%) represented a low level of self-efficacy.

Apart from the overall scores of the scales, an attempt was made to analyze the correlations between the raw scores of the individual scales, taking into consideration social and demographic features with regard to which the respondents were analyzed.

In women, a negative correlation was found between self-efficacy and e age $(r=-0.320, P<0.001)$. The scatter diagrams of GSES score and women's age are presented in Figure 1.

Analyzing the study group affiliation, a negative correlation was reported between the level of self-efficacy and age $(r=-0.408, P<0.001)$ in residents of PNH. A similar, though less marked, correlation was found in participants of UTA ( $r=-0.251, P=0.012)$. In students of UHS, no significant relation was established between the score of GSES and the age of respondents $(r=-0.105, P=0.298)$. Figure 2 presents the correlations analyzed in the study.

Taking into consideration the study group affiliation, a positive correlation was revealed between anger control (CECS) and perception of anger as a trait STAI (X2) in students of UHS ( $r=0.307, P=0.002$ ), which means that the greater the subjective anger control was in participants of UHS, the higher the level of anxiety understood as a personality trait in this group. This relationship was statistically insignificant in the group of UTA $(r=0.040, P=0.693)$ and in the group of PNH $(r=-0.085, P=0.401)$. The detailed scores were presented in Figure 3.

Another correlation was analyzed - between the level of self-efficacy (GSES) and control of negative emotions (CECS) based on the division of respondents into age groups. In respondents aged 60-69 $(r=-0.034, P=0.677)$ and 70-79 ( $r=-0.003, P=0.980)$, no significant correlation was established between the score of GSES and the score of 

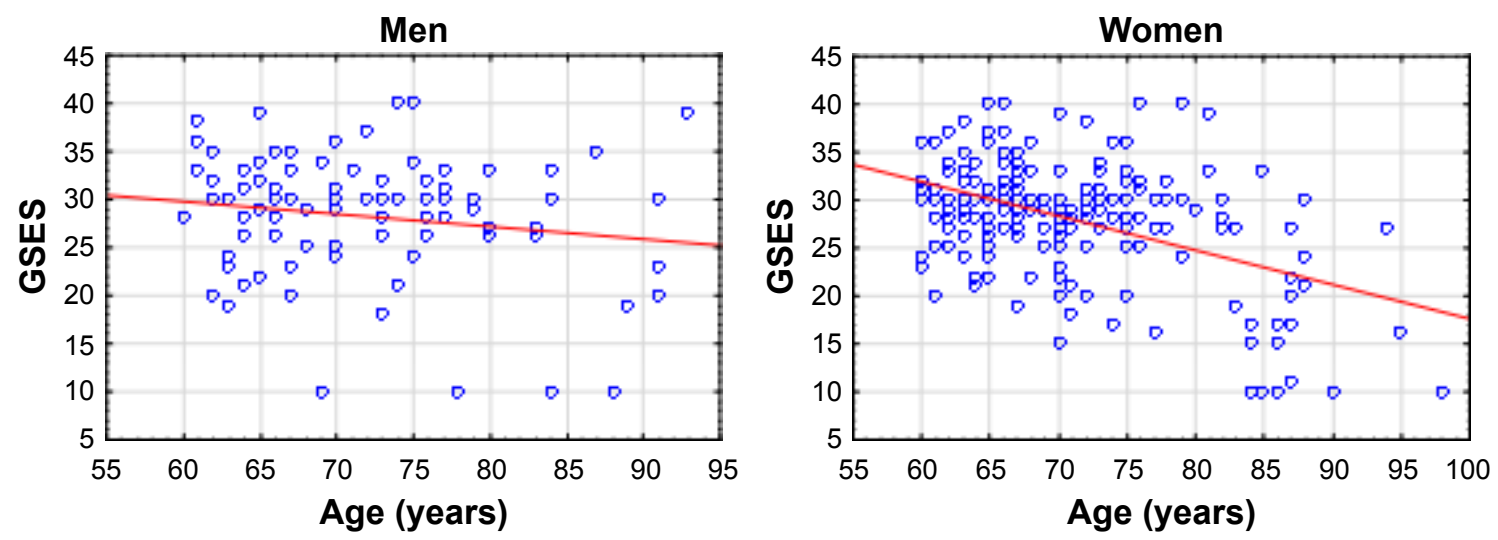

Figure I Scatter diagrams of self-efficacy and age with regard to respondents' gender. Abbreviation: GSES, General Self-Efficacy Scale.

CECS, whereas in the oldest age group (more than 80 years old), significant positive correlations were reported between self-efficacy and anger control $(r=0.413, P=0.005)$, depression $(r=0.423, P=0.004)$, and control of negative emotions in total $(r=0.437, P=0.003)$. This means that the higher the self-efficacy the old aged respondents had, the better they managed anger, depression, and control of negative emotions (anger, depression, anxiety). The detailed scores are shown in Figure 4.

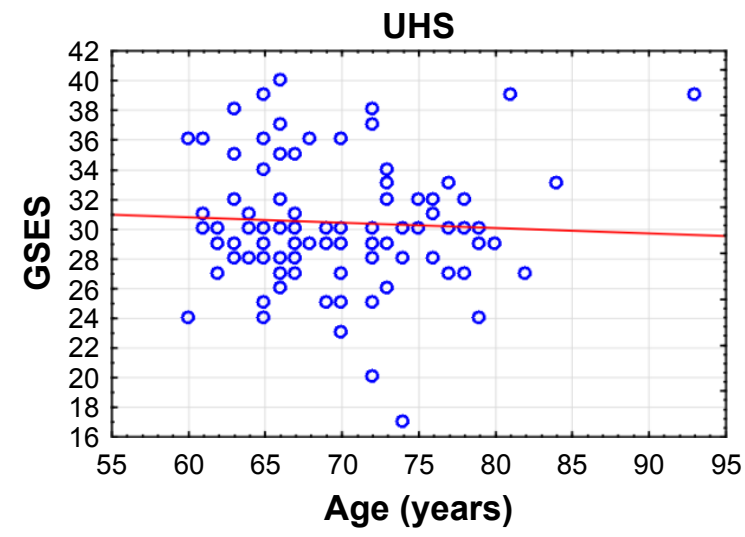

\section{Discussion}

\section{Emotion control}

The majority of earlier studies showing the relation between the stress in psychological terms and the suppression of negative emotions have proved a general unfavorable pattern of suppression of negative emotions. ${ }^{24-26}$ Anger, depression, and anxiety belong to these negative emotions that can be masked to the least degree. Ando et al's ${ }^{9}$ study indicated that emotional suppression of anxiety was significantly

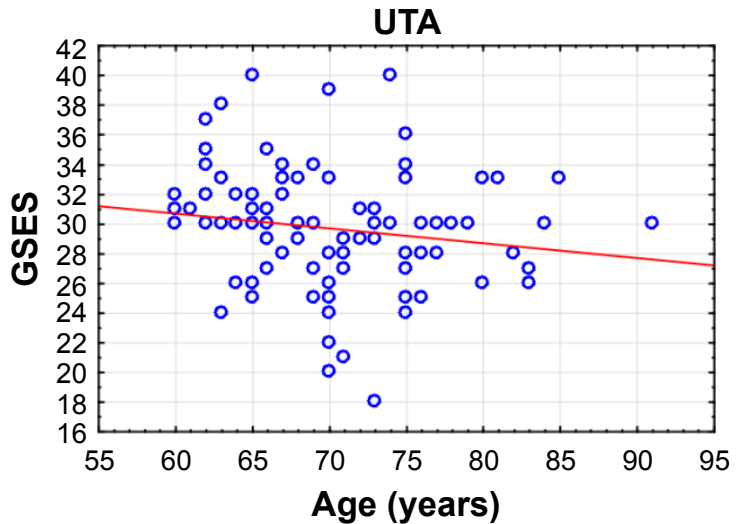

\section{PNH}

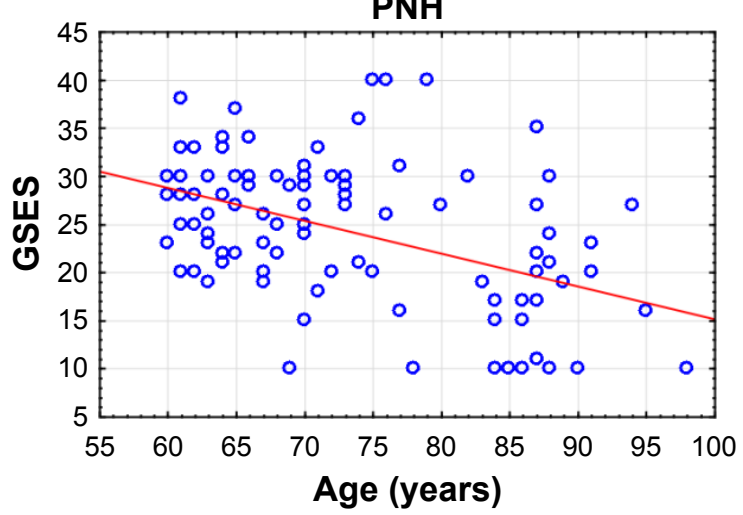

Figure 2 Scatter diagrams of self-efficacy and age with regard to the division into study group affiliation.

Abbreviations: GSES, General Self-Efficacy Scale; PNH, public nursing home; UHS, University of Healthy Seniors; UTA, University of the Third Age. 

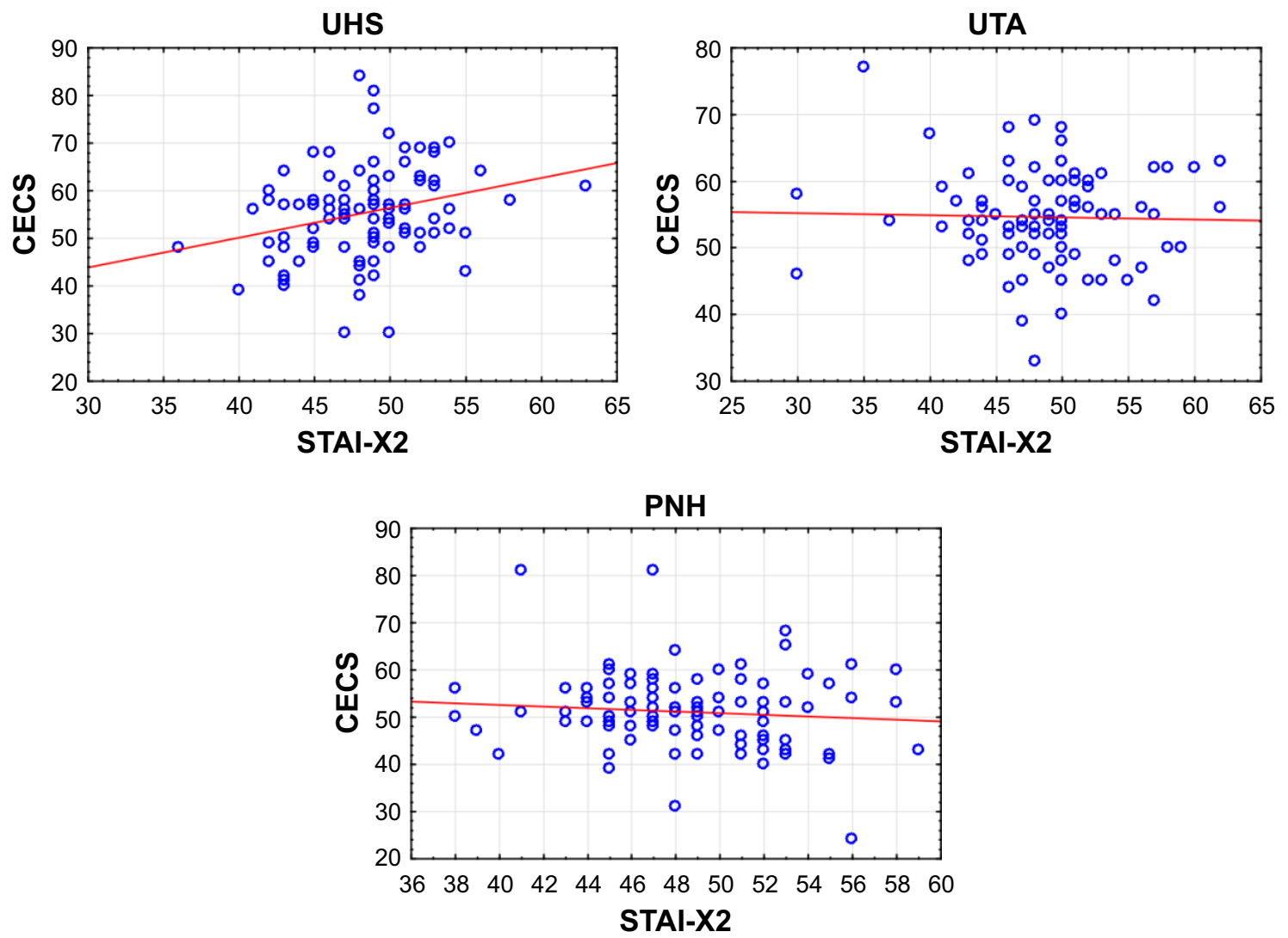

Figure 3 Scatter diagrams of anger control (CECS) and perception of anxiety as a trait (STAI-X2) with the division into the study group affiliation.

Abbreviations: CECS, Courtauld Emotional Control Scale; PNH, public nursing home; STAI, State-Trait Anxiety Inventory; UHS, University of Healthy Seniors; UTA, University of the Third Age.

associated with a higher level of mental suffering but had no effect on suppression of depression and anxiety, though the level of each emotion listed was strongly correlated with each other. In our study, numerous statistically significant correlations were established between the control of negative emotions and the study group affiliation of respondents as well as between the control of anger, anxiety, and depression and self-efficacy.

Our studies proved that the overall score of emotion control regarding the study group affiliation equaled $51.13 \pm 8.28$ in all respondents in total. In the study by Glebocka et al, ${ }^{27}$ the level of emotion control reached $16.5 \pm 4.8$ in the study group and $16.9 \pm 3.7$ in the control group. A much lower level of emotion control could be caused by markedly fewer respondents in the study group $(\mathrm{N}=57)$ and the fact that the study included patients with obstructive sleep apnea (OSA), because OSA can cause anxiety, depression, psychosis, and other pathological mental symptoms. In the study by Symonides et al, ${ }^{28}$ the average score of CECS equaled $54.0 \pm 12.0$ in patients with hypertension. In the same study, differences in the scores of CECS between groups were statistically significant. In our study, the average score of CECS was comparable with the results of the studies mentioned above $^{28}$ and that of the overall values of the Polish population $(50.0 \pm 11.00),{ }^{17}$ which suggests the relevant data collection in our study.

Kossakowska et a ${ }^{8}$ concluded that patients with psoriasis controlled anger, depression, and anxiety to a greater extent compared to the control group. The authors obtained other scores in patients with vitiligo - when comparing these scores with those of healthy people, no differences in control of anger, depression, and anxiety were reported. The authors observed that patients with psoriasis controlled their anger and anxiety more, while depression control was reported at the similar level.

Age is a natural factor in controlling negative emotions, ${ }^{17}$ making control of negative emotions more intensive. In the study by Kossakowska et al, ${ }^{8}$ age proved to be the most vital factor controlling negative emotions in patients with psoriasis. The reason for this could be the fact that psoriasis patients' quality of life is markedly worse in case of seniors. ${ }^{29,30}$ Moreover, the health state of a person with clinically advanced disease most frequently deteriorates with age. Thus, psychological distress was greater in patients aged above $70 .{ }^{31}$ Similarly, in our study, age played a significant role in the control of emotions, and its level decreased with age. 

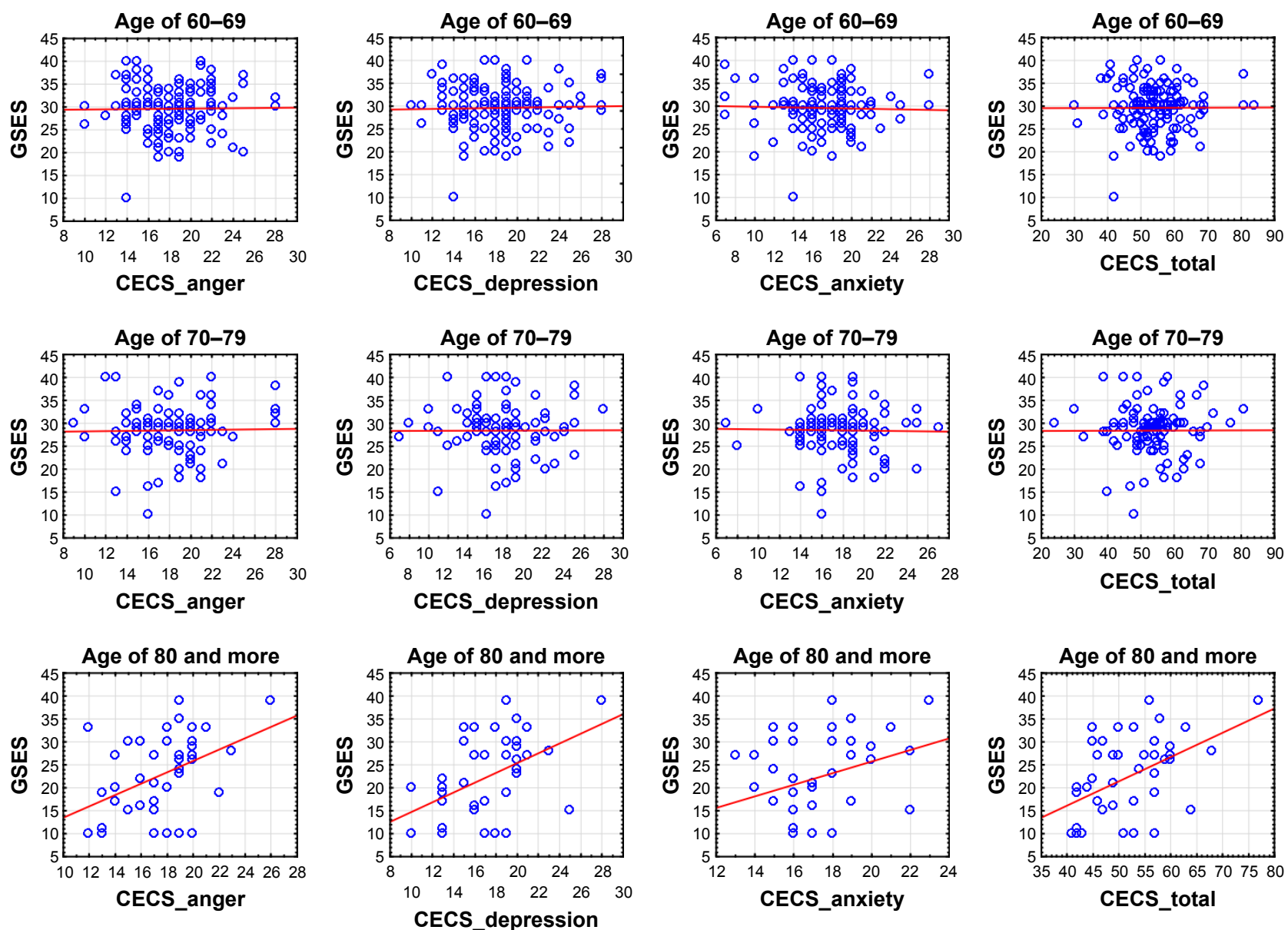

Figure 4 Scatter diagrams of self-efficacy (GSES) and control of emotions (CECS) with division into age groups. Abbreviations: CECS, Courtauld Emotional Control Scale; GSES, General Self-Efficacy Scale.

\section{Level of anxiety}

The scores of STAI as a trait are very frequently associated with earlier development of anxiety disorders, such as, obsessive-compulsive disorders. ${ }^{32}$

In the study by Lee et $\mathrm{al},{ }^{33}$ the mean level of anxiety measured by means of STAI-S scale equaled 34 points $(\mathrm{SD}=16.9)$. The prevalence of clinically significant anxiety (STAI-S $\geq 40$ ) equaled $48.4 \%$ in the study group. Marked anxiety (STAI-S $\geq 55$ ) was identified in $7.5 \%$ of patients suffering from OSA.

In Lancon et al's ${ }^{34}$ study, the mean score of STAI was 43.7. Hosseini et a ${ }^{35,36}$ proved that in 145 (50.9\%) patients, the points of STAI equaled $\geq 40$. In the examination carried out by Remröd et al, ${ }^{37}$ the level of anxiety understood as a state equaled 38.0 \pm 12.2 , while the level of anxiety understood as a trait was 36.5 \pm 11 .9. In their study, Di Mattei et a ${ }^{38}$ reported an insignificantly higher score of anxiety as a state $(42.7 \pm 10.1)$ than in case of anxiety understood as a trait (39.8 \pm 8.06$)$. In both cases, an average level of anxiety was taken into consideration (40-59 points). In the study mentioned, only two patients presented a high level of anxiety understood as a state (above 60 points), while no patient had a high score in case of anxiety understood as a trait. In our study, the highest STAI scores were found compared to the scores of other the other studies mentioned earlier. The level of STAI understood as a state equaled $47.99 \pm 4.48$, while that for anxiety as a trait was $48.55 \pm 4.82$. Higher scores in the subscale of anxiety understood as a trait may suggest that the examined were exposed to chronic stressful situations caused by, eg, family situation, loneliness, isolation, mourning, and so on.

\section{Self-efficacy}

A strong sense of self-efficacy influences greatly an individual's health state and his/her social integration. With regard to feelings, a low level of self-efficacy is related to depression, anxiety, and helplessness. Thus, the level of self-efficacy may support or hinder the motivation for action. ${ }^{39}$ The examinations carried out confirmed significant correlations, especially, between self-efficacy and negative emotions, such as anger and depressive mood. 
In their studies, Poortaghi et a $\mathrm{l}^{40}$ proved that self-efficacy was low and statistically insignificant in both the study group and control group (40 people each, $26.36 \pm 0.84$ vs $28.53 \pm 0.54)$. In the study by Yuasa et $a 1,{ }^{41} 340$ subjects were assessed on subjective level of self-efficacy, and their score was $33.5 \pm 4.5$. Other research into development and promotion of health in local communities also showed a higher level of GSES. ${ }^{42}$ People with high and moderate levels of self-efficacy were more predisposed to additional participation in the activities promoting health compared to people estimating their self-efficacy as being low. ${ }^{43,44}$ In other our study, ${ }^{45}$ the mean score of GSES reached 30.98 in residents of PNH and was not significantly lower $(P=0.062)$, compared to participants of UTA (29.94). The scores obtained in both groups were higher than the overall score (27.32). In our study, the following scores were reported: in students of UHS, 30.45 \pm 4.22 ; in students of UTA, 29.71 \pm 3.88 ; and among residents of $\mathrm{PNH}, 24.38 \pm 7.67$. Unfortunately, the mean score of all respondents $(28.18 \pm 6.14)$ was higher than the mean score in the group of PNH residents, which suggests maintenance of the level of self-efficacy in seniors participating actively in the UTA (including UHS) and a decrease in the level of self-efficacy in residents of PNH. It is worth mentioning that analyzing the scores obtained in our study and comparing them to the scores of other studies revealed that the level of self-efficacy was similar.

\section{Limitations of the study}

The main limitation of the study in authors' opinion is the small size of the study groups. In addition, the study was conducted only in one city (Bialystok), which may not reflect the results for the whole country. The study involved only residents of Bialystok above 60 years of age, because the authors are employees of the Medical University of Bialystok and therefore had the easiest access to the inhabitants of this city.

\section{Conclusion}

1. The social and demographic features (gender, group affiliation, age) analyzed in the study correlated significantly with the control of negative emotions, the level of anxiety, and self-efficacy.

2. The study group affiliation was a key variable conditioning the relationship between the analyzed features.

3. The elderly residents of public nursing homes belonged to the group showing more negative results compared to other two study groups.

4. The study respondents were characterized by the relatively high perception of anxiety, which may be as a result of the health and social problem present in this age group.
5. In order to improve the quality of life, the study population should reduce level of perceived anxiety and increase the control of negative emotions and self-efficacy by social integration of seniors.

6. The study scores in CECS, STAI, and GSES do not deviate from the world norms obtained by other researchers.

\section{Acknowledgments}

The research was funded under grant no N/ST/MN/16/ 001/3310 of the Ministry of Science and Higher Education. The funders had no role in study design, data collection and analysis, decision to publish, or preparation of the manuscript.

\section{Author contributions}

Mateusz Cybulski and Elzbieta Krajewska-Kulak contributed to the study design; Mateusz Cybulski and Lukasz Cybulski contributed to data collection. All authors contributed toward data analysis, drafting and critically revising the paper and agree to be accountable for all aspects of the work.

\section{Disclosure}

The authors report no conflicts of interest in this work.

\section{References}

1. Editorial. Aging and health - an agenda half completed. Lancet. 2015; 386:1509.

2. World Health Organization. The European Health Report 2012. Charting the way to well-being. Copenhagen: WHO; 2013.

3. Mossakowska M, Wiecek A, Bledowski P, editors. Aspekty medyczne. psychologiczne. socjologiczne $i$ ekonomiczne starzenia się ludzi $w$ Polsce. [Medical, psychological, sociological and economic aspects of aging people in Poland]. Poznan, Poland: Wydawnictwa Medyczne Termedia; 2012. Polish.

4. Cavallo M, Hunter EM, van der Hiele K, Anqilletta C. Computerized structured cognitive training in patients affected by early-stage Alzheimer's disease is feasible and effective: a randomized controlled study. Arch Clin Neuropsychol. 2016;31(8):868-876.

5. Borghi M, Carletto S, Ostacoli L, et al. Decline of neuropsychological abilities in a large sample of patients with multiple sclerosis: a two-year longitudinal study. Front Hum Neurosci. 2016;10:282.

6. Cavallo M, Trivelli F, Adenzato M, et al. Do neuropsychological and social cognition abilities in schizophrenia change after intensive cognitive training? A pilot study. Clin Neuropsychiatry. 2013;10(5): 202-211.

7. Enrici I, Adenzato M, Ardito RB, et al. Emotion processing in Parkinson's disease: a three-level study on recognition, representation, and regulation. PLoS One. 2015;10(6):e0131470.

8. Kossakowska MM, Ciescinska C, Jaszewska J, Placek WJ. Control of negative emotions and its implication for illness perception among psoriasis and vitiligo patients. J Eur Acad Dermatol Venereol. 2010;24(4): 429-433.

9. Ando N, Iwamitsu Y, Kuranami M, et al. Psychological characteristics and subjective symptoms as determinants of psychological distress in patients prior to breast cancer diagnosis. Support Care Cancer. 2009; 17(11):1361-1370.

10. Watson M, Greer S. Development of a questionnaire measure of emotional control. J Psychosom Res. 1983;27(4):299-305. 
11. Quartana PJ, Laubmeier KK, Zakowski SG. Psychological adjustment following diagnosis and treatment of cancer: an examination of the moderating role of positive and negative emotional expressivity. $J$ Behav Med. 2006;29(5):487-498.

12. Montgomery GH, David D, Goldfarb AB, et al. Sources of anticipatory distress among breast surgery patients. J Behav Med. 2003; 26(2):153-164.

13. Ollonen P, Lehtonen J, Eskelinen M. Anxiety, depression, and the history of psychiatric symptoms in patients with breast disease: a prospective case-control study in Kuopio, Finland. Anticancer Res. 2005; 25(3c):2527-2533.

14. Clewett D, Bachman S, Mather M. Age-related reduced prefrontalamygdala structural connectivity is associated with lower trait anxiety. Neuropsychology. 2014;28(4):631-642.

15. Richardson TM, Simning A, He H, Conwell Y. Anxiety and its correlates among older adults accessing aging services. Int J Geriatr Psychiatry. 2011;26(1):31-38.

16. Jachimowicz V, Kostka T. Assessment of self-efficacy in the residents of older people home. Gerontol Pol. 2009;17(1):23-31.

17. Juczynski Z. Narzedzia pomiaru w promocji i psychologii zdrowia. [Tools of measurement in health promotion and health psychology]. Warsaw, Poland: Pracownia Testow Psychologicznych Polskiego Towarzystwa Psychologicznego; 2001. Polish.

18. Locke EA, Latham GP. Building a practically useful theory of goal setting and task motivation. A 35-year odyssey. Am Psychol. 2002; 57(9):705-717.

19. Cattell RB. Anxiety and motivation: theory and crucial experiments. In: Spielberger CD, editor. Anxiety and Behavior. New York, NY: Academic Press; 1966.

20. Wrzesniewski K, Sosnowski T, Matusik D. Inwentarz Stanu i Cechy Leku STAI. Polska adaptacja STAI. [State-Trait Anxiety Inventory STAI. Polish adaptation of STAI.]. Warsaw, Poland: Pracownia Testow Psychologicznych Polskiego Towarzystwa Psychologicznego; 2002. Polish.

21. Knight RG, Waal-Manning HJ, Spears GF. Some norms and reliability data for the State-Trait Anxiety Inventory and the Zung Self-Rating Depression scale. Br J Clin Psychol. 1983;22(Pt 4):245-249.

22. Addolorato G, Ancona C, Capristo E, et al. State and trait anxiety in women affected by allergic and vasomotor rhinitis. J Psychosom Res. 1999;46(3):283-289.

23. Kvaal K, Ulstein I, Nordhus IH, Engedal K. The Spielberger State-Trait Anxiety Inventory (STAI): the state scale in detecting mental disorders in geriatric patients. Int J Geriatr Psychiatry. 2005;20(7):629-634.

24. Classen C, Koopman C, Angell K, Spiegel D. Coping styles associated with psychological adjustment to advanced breast cancer. Health Psychol. 1996;15(6):434-437.

25. Cordova MJ, Giese-Davis J, Golant M, et al. Mood disturbance in community cancer support groups-the role of emotional suppression and fighting spirit. J Psychosom Res. 2003;55(5):461-467.

26. Ho RT, Chan CLW, Ho SM. Emotional control in Chinese female cancer survivors. Psychooncol. 2004;13(11):808-817.

27. Glebocka A, Kossowska A, Bednarek M. Obstructive sleep apnea and the quality of life. J Physiol Pharmacol. 2006;57(Suppl 4):111-117.

28. Symonides B, Holas P, Schram M, Śleszycka J, Bogaczewicz A, Gaciong Z. Does the control of negative emotions influence blood pressure control and its variability? Blood Press. 2014;23(6):323-329.
29. Gupta MA, Gupta AK, Watteel G. Early onset ( $<$ age 40 years) psoriasis is associated with greater psychopathology than late onset psoriasis. Acta Derm Venereol. 1996;76(6):464-466.

30. Sampogna F, Chren MM, Melchi CF, et al. Age, gender, quality of life and psychological distress in patients hospitalized with psoriasis. $\mathrm{Br} J$ Dermatol. 2006;154(2):325-331.

31. Sampogna F, Tabolli S, Mastroeni S, et al. Quality of life impairment and psychological distress in elderly patients with psoriasis. Dermatology. 2007;215(4):341-347.

32. Wang X, Cui D, Wang Z, et al. Cross-sectional comparison of the clinical characteristics of adults with early-onset and late-onset obsessive compulsive disorder. J Affect Disord. 2012;136(3):498-504.

33. Lee SA, Han SH, Ryu HU. Anxiety and its relationship to quality of life independent of depression in patients with obstructive sleep apnea. J Psychosom Res. 2015;79(1):32-36.

34. Lancon C, Martinelli M, Michel P, et al. Comorbidités psychiatriques et qualité de vie chez les sujets adultes à haut potentiel intellectuel : relations avec l'estime de soi. [Psychiatric comorbidities and quality of life in adult individuals with high potential: relationships with selfesteem.] Presse Med. 2015;44(5):e177-e184. French.

35. Hosseini SH, Ghaemian A, Mehdizadeh E, et al. Levels of anxiety and depression as predictors of mortality following myocardial infarction: a 5-year follow-up. Cardiol J. 2014;21(4):370-377.

36. Hosseini SH, Ghaemian A, Mehdizadeh E, Ashraf H. Contribution of depression and anxiety to impaired quality of life in survivors of myocardial infarction. Int J Psychiatry Clin Pract. 2014;18(3):175-181.

37. Remröd C, Sjöström K, Svensson Å. Subjective stress reactivity in psoriasis - a cross sectional study of associated psychological traits. BMC Dermatol. 2015;15:6.

38. Di Mattei VE, Carnelli L, Bernardi M, et al. An investigative study into psychological and fertility sequelae of gestational trophoblastic disease: the impact on patients' perceived fertility, anxiety and depression. PLoS One. 2015;10:e0128354.

39. Schwarzer R, Fuchs R. Self efficacy and health behaviors. In: Connor M, Norman P, editors. Predicting Health Behavior: Research and Practice with Social Cognition Models. Buckingham, UK: Open University Press; 1996:163-196.

40. Poortaghi S, Baghernia A, Golzari SE, Safayian A, Atri SB. The effect of home-based cardiac rehabilitation program on self efficacy of patients referred to cardiac rehabilitation center. BMC Res Notes. 2013;6:287.

41. Yuasa M, Shirayama Y, Osato K, Miranda C, Condore J, Siles R. Crosssectional analysis of self-efficacy and social capital in a communitybased healthy village project in Santa Cruz, Bolivia. BMC Int Health Hum Rights. 2015;15:15.

42. Kwong EW, Kwan AY. Participation in health-promoting behaviour: influences on community-dwelling older Chinese people. $J$ Adv Nurs. 2007;57(5):522-534.

43. Kaiser BL, Brown RL, Baumann LC. Perceived influences on physical activity and diet in low-income adults from two rural counties. Nurs Res. 2010;59(1):67-75.

44. Tayama J, Yamasaki H, Tamai M, et al. Effect of baseline self-efficacy on physical activity and psychological stress after a one-week pedometer intervention. Percept Mot Skills. 2012;114(2):407-418.

45. Cybulski M, Krajewska-Kulak E, Jamiolkowski J. Preferred health behaviors and quality of life of the elderly people in Poland. Clin Interv Aging. 2015;10:1555-1564
Clinical Interventions in Aging

\section{Publish your work in this journal}

Clinical Interventions in Aging is an international, peer-reviewed journal focusing on evidence-based reports on the value or lack thereof of treatments intended to prevent or delay the onset of maladaptive correlates of aging in human beings. This journal is indexed on PubMed Central, MedLine,

\section{Dovepress}

CAS, Scopus and the Elsevier Bibliographic databases. The manuscript management system is completely online and includes a very quick and fair peer-review system, which is all easy to use. Visit http://www.dovepress. com/testimonials.php to read real quotes from published authors. 